\title{
Categorías, negociación y conflicto: indígenas "montaraces" y "reducidos" en la frontera norte de Santa Fe (1857-1864)
}

Francisco Mora*

Fecha de recepción: 2 de enero de 2019. Fecha de aceptación: 2 de agosto de 2019

\section{Resumen}

Palabras clave montaraces reducidos frontera Chaco

Durante las décadas de 1850 y 1860 el Estado argentino intentó avanzar sobre el territorio indígena del Chaco Austral. A través del análisis de partes militares e informes de misioneros situados principalmente en enclaves fronterizos en el norte de la provincia de Santa Fe, seguiremos la trayectoria de diversos actores indígenas considerados alternativamente como aliados y/o enemigos de los gobiernos nacionales y provinciales. Buscamos identificar las estrategias políticas llevadas adelante por estos y relacionarlas con las categorías clasificatorias presentes en los documentos, esperando develar una dinámica social y política sobre las poblaciones indígenas que los registros oficiales tienden a ocultar.

Categories, negotiation and conflict: "montaraces" and "reducidos" Indians on the northern border of Santa Fe (1857-1864)

\section{Abstract}

During the decades 1850 and 1860, the Argentine Government tried to advance on the indigenous territory of the southern Chaco. Through an analysis of military and missionary reports, mainly from the border of north of the Santa Fe province, we will follow the path of various indigenous actors that the national and provincial governments considered, alternatively, as allies and/ or enemies. We seek to identify the political strategies pursued by the latter and link them to the classification categories present in the documents, as we hope to reveal social and political dynamics of indigenous peoples that official records tend to conceal.

\footnotetext{
* Facultad de Ciencias Naturales y Museo. Universidad Nacional de La Plata (UNLP). La Plata, Argentina. E-mail: franciscomorafn@gmail.com
} 
Hacia fines de la década de 1850 y comienzos de 1860 los fuertes cambios involucrados en la organización del Estado argentino impactaron en el manejo y administración de los espacios de frontera heredados de la etapa colonial. Las progresivas políticas de colonización del espacio rural y la expansión de los límites territoriales sobre los territorios ocupados por pueblos indígenas fueron dos de los principales procesos que se iniciarán en la Confederación Argentina (1853) y luego continuarán en la República a partir de 1862.

Los territorios que limitaban al norte y sur del territorio argentino eran pensados como espacios "libres", poblados por sociedades que debían ser civilizadas. En esta clave se proyectó sobre ellos la posibilidad de integrarlos al sistema productivo nacional y de poblarlos con determinadas comunidades inmigrantes europeas, o bien con poblaciones indígenas reducidas.

En particular, en la provincia de Santa Fe el territorio que delimitaba con el Chaco estaba caracterizado por la articulación de enclaves con características diferentes, tanto por los objetivos con que los habían erigido diversos Estados, como por los actores que interactuaban en ellos. Allí los primeros asentamientos misionales datan de mediados de siglo XVIII, y algunos permanecieron poblados hasta el periodo de nuestro interés. A su vez los fortines, primero impulsados por las políticas borbónicas y luego por los Estados provinciales y nacional, pasarían a ser enclaves fundamentales para pensar la expansión del territorio nacional. Por su parte, a partir de 1856 las colonias agrícolas introdujeron al escenario del norte santafesino inmigrantes europeos y norteamericanos.

A la hora de aproximarnos a estas poblaciones en las fuentes se nos presentó un problema particular: aquellas denominaciones utilizadas durante el siglo XVIII para nombrar al "otro indígena" fueron reemplazadas por nuevos rótulos. Este fenómeno presente en la documentación permitió la construcción de interrogantes orientados a identificar los procesos involucrados en la construcción de la identidad indígena en esta frontera, así como a la integración de un aspecto ideológico en el dispositivo militar de la frontera.

Este trabajo busca relacionar dos aspectos: la producción históricamente situada de categorías sobre un "otro" realizada por los actores militares de la frontera, con las prácticas políticas desarrolladas por las poblaciones indígenas, los funcionarios militares y el Estado. Para este fin, analizaremos la correspondencia oficial generada por diferentes estratos de la administración militar de la frontera, las listas de revista de los cuerpos que la integraban y la variada correspondencia personal producida por sus oficiales. A su vez, reconstruiremos las trayectorias del cacique Bonifacio y la de algunos integrantes de su parcialidad entre 1857 y 1862, como así también la de Manuel Días entre 1858 y 1864 buscando identificar y caracterizar las principales formas de negociación y confrontación puestas en marcha por los jefes indígenas. Finalmente, pondremos en tensión las categorías producidas por los funcionarios y por el Estado revelando, de esta manera, una dinámica social y política que escapa a las interpretaciones generadas por estos actores.

\section{La frontera con el Chaco}

En primer lugar caracterizaremos el territorio del Chaco y el proceso de conformación de las fronteras, principalmente la sección ubicada al norte de la ciudad de Santa Fe, como un complejo espacio de interacción. Luego nos 
1. Para una visión más detallada de las caracterizaciones geográficas y fitogeográficas, ver Tola, et al. (2013).

2. En este contexto podemos situar las producciones de Martin Dobrizhoffer ([1783] 1967) sobre los abipones y las de Florian Paucke ([1942] 2010) sobre los mocovíes, entre otras. Para más información sobre las reducciones indígenas durante el siglo XVIII ver Nesis (2005), Paz (2007) y Lucaioli (2011).

3. Para una profundización de la constitución de los diversos sectores de la frontera con el Chaco durante el periodo colonial, ver Lucaioli y Nacuzzi (2010).
4. El estado de las misiones franciscanas en el norte de Santa Fe en el periodo que abarca desde las guerras independentistas hasta la creación de la Confederación Argentina se encuentra menos estudiado, aunque hay referencias del mismo en Cervera (1970) y Green (2007).

5. Estas reducciones formaban parte de la diócesis de Santa Fe, la cual incluiría posteriormente nuevas misiones fundadas en los territorios de Chaco y Formosa (Dalla-Corte Caballero y Vázquez Recalde, 2010; Dalla-Corte Caballero, 2012). concentraremos en las formas en que las poblaciones indígenas son representadas en el registro documental militar.

Las fronteras ubicadas en el actual territorio del chaco austral se conformaron durante el periodo colonial en torno a las principales ciudades emplazadas sobre el cauce del río Paraná y sus afluentes, como Santa Fe de la Vera Cruz y Corrientes. ${ }^{1} \mathrm{~A}$ éstas se agregaron aquellas ciudades que conectaban con la ruta hacia el altiplano boliviano: Córdoba, Santiago del Estero, San Miguel de Tucumán y Salta.

Durante el siglo XVIII las autoridades coloniales, buscando establecer lazos de "amistad" con las poblaciones indígenas de las áreas que no podían controlar territorialmente (Lázaro Avila, 1999), iniciaron una política que favoreció el asentamiento en establecimientos dedicados a su evangelización. Estos fueron administrados inicialmente por la orden jesuita hasta 1767 , cuando la Compañía de Jesús fue expulsada de los territorios coloniales. ${ }^{2}$ Además, desplegaron una diplomacia orientada a la formación de escuadrones de lanceros indígenas para reforzar la vigilancia de estos enclaves (Lucaioli y Nacuzzi, 2010) frente a la posibilidad de incursiones de grupos indígenas hostiles o bien de ejércitos enemigos, principalmente vinculados al avance portugués (Levaggi, 2000).

Al mismo tiempo, según los distintos segmentos fronterizos y las poblaciones involucradas, los indígenas privilegiaron el contacto con los enclaves coloniales, utilizándolos principalmente como fuente de aprovisionamiento de artefactos, ganado, vicios y demás elementos (Lucaioli, 2009, 2011). Estas estrategias de intercambio y abastecimiento complementaban las actividades de recolección y caza tradicionales que los llevaba a movilizarse dentro de grandes extensiones del territorio chaqueño. Así, al tiempo que se crearon espacios de interacción surgieron nuevas prácticas relacionadas con la negociación, la legitimación del poder y de los liderazgos ${ }^{3}$ (Nesis, 2005; Citro, 2006; Lucaioli, 2011). Se promovió entonces el trato con líderes y caciques con el objetivo de transformarlos en jefes permanentes de las parcialidades a las cuales representaban, lo cual contrastaba con las prácticas políticas y las formas de construir liderazgo de los pueblos chaqueños en general. Sabemos por las crónicas de los jesuitas en el siglo XVIII, y por los trabajos que las han analizado en profundidad (Nesis, 2005; Citro, 2007), que la organización política de estas poblaciones indígenas se fundaba principalmente en la deliberación y la toma de decisiones en grupo. Estas prácticas consensuales seleccionaban liderazgos caracterizados por cualidades guerreras, chamánicas y de valentía. Luego, mediante la intervención de los agentes estatales y a través de regalos, el otorgamiento de títulos, raciones, sueldos y tratos preferenciales, se intentó fortalecer y a la vez sujetar a estos líderes a las prescripciones políticas de las autoridades de turno.

En 1818, en el contexto específico del sector santafesino de la frontera del chaco austral y a partir de las iniciativas del gobernador Estanislao López, las reducciones indígenas pasaron a ser administradas por la orden franciscana; ${ }^{4}$ aunque durante el periodo abarcado entre 1824 y 1852 muchas fueron abandonadas o sufrieron traslados sucesivos. Hacia la década de 1860 esta Orden logró reconstruir y poblar las reducciones de San Francisco Javier de Mocovíes, San Jerónimo del Sauce de Abipones, Santa Rosa de Calchines -algunos antiguos pobladores de San Javier- y Nuestra Señora de Cayastá -inicialmente fundada para indígenas Charrúas traídos desde el Río Uruguay- (Dalla-Corte Caballero, 2012)..$^{5}$ A este nuevo impulso que ordenó la frontera con fortines y misiones se 
agregaron las colonias agrícolas de inmigrantes europeos y norteamericanos a partir de 1856 (Mafucci Moore, 2007; Dosztal, 2013; Ratto, 2013).

\section{El ordenamiento militar de la frontera norte santafesina}

Muchos trabajos se han dedicado al estudio de las fuerzas militares en la frontera santafesina; algunos tratan específicamente sobre las transformaciones de los enclaves militares y los fortines (Alemán, 1970), otros caracterizan a los regimientos que sirvieron a la construcción de la línea defensiva durante el siglo XVIII y XIX (Ratto y Fradkin, 2011), o abordan el proceso de formación de cuerpos de lanceros indígenas y el trato con diferentes líderes de parcialidades (Green, 2005, 2011; Molina y Green, 2015). Sin embargo, debemos señalar que la gran mayoría de estos trabajos se concentra en la segunda mitad del siglo XVIII y en los comienzos del siguiente, o bien -los menos- en la segunda mitad del siglo XIX. Ello deja un espacio temporal menos atendido, que se extiende desde el periodo independentista hasta la batalla de Caseros. Las relaciones que se hayan gestado entre el gobierno provincial, sus autoridades, el clero y las poblaciones indígenas durante este tiempo, salvo alguna excepción (Alemán, 1970; Green, 2007), permanecen sin ser estudiadas en profundidad.

Durante el mencionado periodo fueron los gobernadores, Estanislao López y luego su hermano Juan Pablo, los principales ordenadores de la política con los mocovíes y los abipones. Después de una serie de conflictos con ambos se lograron repoblar las reducciones de San Pedro y San Javier Mocovíes, y más tarde se fundó San Jerónimo del Sauce -al oeste de la ciudad de Santa Fe- para abipones. Según los autores anteriormente nombrados es a partir de estas políticas que nuevamente se conforman los cuerpos de lanceros indígenas, los cuales participan en numerosas campañas militares junto al gobierno, incluso en la frontera sur de la provincia rechazando los ataques ranqueles (Alemán, 1970). Estos cuerpos se transformarán así en regimientos fundamentales para las guarniciones de los fortines de la frontera norte.

Llegamos de esta forma a la década de 1850, cuando por primera vez el gobierno de la Confederación Argentina definió una jurisdicción nacional militar en la frontera -anteriormente administrada en forma exclusiva por el gobierno de cada provincia-, nombrando como comandante militar sobre el Chaco al coronel Alfredo Du Graty, en septiembre de 1858. Esta frontera se extendía desde la colonia de San Javier, cercana al cauce del río Paraná en el este de la provincia de Santa Fe, siguiendo la línea del cauce del río Salado a partir de la Esquina Grande hasta el Bracho en Santiago del Estero. La misma estaba resguardada por los regimientos 5, 8 y 9 de Caballería y el 5 de Infantería de línea. Fueron apoyados por las Guardias Nacionales reclutadas de la población de cada provincia. En la frontera santafesina también cumplirán cierta función defensiva los Regimientos auxiliares de Lanceros Indígenas. ${ }^{6}$ A partir de este momento la frontera norte de esta provincia se subdividirá, a su vez, en tres sectores: un sector oriental -San José y Calchines-, uno central -fortines Libertad, General López, Campo de Álvarez y San Pedro- y uno occidental -Sauce, Romero y 6 de Julio- (Zampa, 2019).

De esta forma, el Ministerio de Guerra y Marina junto a la inspección general de armas deberán articular la política de defensa y las acciones punitivas en el Chaco de manera coordinada con los gobiernos de las provincias de Santiago del Estero, Córdoba y Santa Fe. ${ }^{7}$ La política reduccional junto a la reorganización militar de la frontera atravesarán un momento de nuevo impulso a partir
6. SHE-FC. Caja 1, Docs n ${ }^{\circ} 173-175$. Establece los límites y extensión de la frontera, además de las fuerzas militares que la componen.

7. Esta articulación, junto con la empresa de movilizar la frontera hacia el cauce del Salado, fue objeto de conflictos entre los diversos regimientos y la autoridad del ministerio, en particular con Du Graty. Las sublevaciones, las quejas y las intrigas no son excepciones en la correspondencia oficial y la personal de los oficiales involucrados. Para más detalles consultar el trabajo, ya clásico, de Alemán (1970). 
del cual, por un lado, se intentará restablecer relaciones diplomáticas con los jefes indígenas (Levaggi, 2000; Green, 2011; Dalla-Corte Caballero, 2012), con el objetivo de reducirlos y asentarlos en las localizaciones administradas por la Orden Franciscana; mientras, por otro lado, se propiciarán diversas incursiones bélicas dentro del territorio del Chaco con el objetivo de castigar a las poblaciones a las cuales se les atribuían robos de ganado, toma de cautivos y algunos homicidios.

\section{Las categorías sobre el "otro indígena" en el contexto de la frontera}

La reorganización militar de la frontera, con sus negociaciones, intercambios y entradas punitivas, no fue un mero reordenamiento de los enclaves militares o misionales. Tampoco fue un simple avance de una línea o barrera, como pretendía el ministro Du Graty. Esta política implicó otros aspectos simbólicos e ideológicos también relevantes a la hora de pensar las relaciones del Estado con las poblaciones indígenas. Las autoridades militares y eclesiásticas tendieron a ordenar en torno a nuevos rótulos y visiones al "otro indígena". La identificación de estas denominaciones en las fuentes documentales nos hablan del momento en el cual se enunciaron y dan cuenta del estado de las relaciones existentes (Nacuzzi y Lucaioli, 2017), suscitando una serie de preguntas. La primera, gira en torno a cómo se hace presente el "otro indígena" en los registros documentales de esta frontera -¿qué variantes existían para clasificarlos?-; y la segunda interroga sobre los aspectos adicionales que se asocian a estos rótulos -tales como ¿qué visiones expresan los rótulos y cómo se relacionan con otros conceptos y términos empleados?

Si nos aproximamos a los diferentes partes militares, la correspondencia personal de los oficiales y los informes de los curas doctrineros de las misiones podemos observar que los rótulos étnicos previamente empleados para referirse a las poblaciones indígenas -principalmente durante el siglo XVIII- fueron reemplazados por otros que se refieren a su condición política: montaraces y reducidos. Ya no encontramos en las fuentes referencias a "mocovíes", "abipones" o "tobas", el término montaraz reemplazó y, en el mejor de los casos, se superpuso a aquellos.

Haciendo referencia a la provincia de Santiago del Estero durante el periodo colonial, Farberman señala que el término montaraz aludía a la población campesina, que incluía a "indios cristianos y salvajes, pudientes y conchabados y comerciantes de diversa calaña que conformaban un heterogéneo conjunto de montaraces en la dinámica fronteriza del Salado" (Farberman, 2006: 14), cuyo sustento, durante parte del año, era la recolección de algarroba, mistol, miel silvestre, etc. con fines de consumo e intercambio. Ya entrado el siglo XIX, Ratto y Fradkin (2011) entienden a los montaraces como aquellas poblaciones que, según las fuentes, se ubicaban en una posición de marginalidad con respecto a los tratos diplomáticos con las autoridades provinciales, combinando alianzas esporádicas con indígenas reducidos. Otros autores siguen esta línea, agregando que probablemente hayan participado de redes comerciales establecidas con la sociedad criolla, basadas en el intercambio de ganado (Citro, 2006; Maffucci Moore, 2007). En definitiva, los indígenas considerados como montaraces en las fuentes revisadas por estos autores son aquellos que asaltaban los puestos criollos de la frontera con el fin de llevarse el ganado. 
La mayor parte de los oficiales de la frontera que utilizaban este rótulo lo hacía principalmente al relatar acontecimientos conflictivos, frecuentemente estos implicaban una incursión indígena seguida de robo de ganado que solía denominarse invasión. Luego de ser sentida, esta partida era perseguida y, en algunos casos, reprimida a fin de recuperar de esa manera una parte o la totalidad de la hacienda. ${ }^{8}$ Esta secuencia recurrente parecía imponerse como el principal patrón de acontecimientos que conformaba las relaciones con el "otro indígena" en el norte de Santa Fe y el este de Córdoba y Santiago del Estero. Sin embargo, los registros analizados nos permitieron acceder, como señala Nacuzzi (2018: 209), al menos en forma fragmentaria a la cotidianeidad de las actividades desarrolladas en los enclaves militares de la frontera y, en ocasiones, a los nombres de los jefes indígenas principales, las localizaciones específicas "tierra adentro" y a información adicional muchas veces presentada en un segundo plano.

En el contexto que analizamos aquí, el montaraz se convierte en un individuo al que hay que perseguir, reprimir y asesinar. En este sentido la Orden General impartida por el comandante Du Graty en noviembre de 1858 a los oficiales a cargo de los diferentes sectores de la frontera santafesina expresaba que:

$1^{\circ}$ Todo indio o china montaraz encontrado con robo o sin él sera muerto en el lugar mismo donde fuere encontrado si es que no viene enviado en comisión por algún cacique, en este caso se le detendrá hasta averiguar la verdad del hecho de la comisión alegado por él. ${ }^{9}$

Además de establecer duras reprimendas a cualquier transgresión de los límites de la frontera, esta disposición manifestaba también las posibilidades que los indígenas tenían para movilizarse dentro de la misma. En un segundo artículo establecía los límites para la movilidad de los indígenas pobladores de las colonias en manos de los franciscanos. Cualquier movimiento de individuos indígenas dentro de los límites formales de la frontera planteados por el Ministerio de Guerra y Marina era ilegal, pudiendo ser su resultado la cárcel o bien la muerte. Esta distinción dependía del lugar desde el cual proviniera el indígena, si "atravesaba" la frontera desde "tierra adentro" o si simplemente se había desplazado fuera de la reducción. ${ }^{10}$ De esta forma, el estado nacional encontraba la forma de circunscribir en un marco espacial específico a las poblaciones indígenas, utilizando categorías sociopolíticas especiales: los montaraces y los reducidos (Boccara, 2003).

Para visualizar en las fuentes documentales a la población indígena reducida de las décadas centrales del siglo XIX debimos recurrir a otro tipo de registros, como las listas de revista de las Guardias Nacionales de la provincia de Santa $\mathrm{Fe}^{11}$ algunos censos de población ${ }^{12}$ y los registros acerca de la entrega de reses para el consumo de las tropas, entre otras diversas fuentes. ${ }^{13}$ No contamos con descripciones de la vida cotidiana como las que realizaran los jesuitas durante el siglo XVIII, aunque sí existen relatos recopilados y editados tiempo después como, por ejemplo, el del prefecto de misiones Vicente Caloni (Caloni, 1897). Tanto la entrega de reses, regalos o vicios, como los censos y los relatos editados nos proporcionan los nombres de diferentes actores indígenas que figuran como corregidores, caciques, soldados o incluso oficiales -recibiendo pagos del estado o no.

Retomando el análisis previo, comprendemos entonces que la documentación construye una asociación y una correspondencia entre el rótulo de montaraz, la idea de "invasión" y una dinámica social particular basada en el robo de
8. SHE-FC. Caja 1, Docs n ${ }^{\circ} 128,188-$ 189, 207-209, etc.

9. SHE-FC. Caja 1, Doc $\mathrm{n}^{\circ} 187$, $26 / 11 / 1858$. Se ha respetado la redacción original.

10. SHE-FC. Caja 1, Doc. $n^{\circ} 187$, 26/11/1858.

11. SHE. Listas de Revista, Libro 231. 12. AGPSF. Archivo de Gobierno, T. 20, fs. 1132-1133. Censo de los habitantes de Santa Rosa de Calchines (1860).

13. A este listado podemos agregar la correspondencia entre los funcionarios del Poder Ejecutivo de la provincia de Santa Fe y las autoridades militares de cada punto de la frontera; correspondencia entre los jueces de paz de localidades del norte de la provincia, quienes reportan diferentes acontecimientos al Estado provincial. En su mayor parte estos documentos se encuentran entre los Archivos de Gobierno del AGPSF. 
14. AGPSF. Archivo de Gobierno, T. 16, fs. 1068-1077. Extracto del diario de viaje de los días en que los indios han venido a visitar el vapor, desde el 3/3/1857 hasta el 21/3/1857.

15. “[...] él estaba completamente autorizado por el Excelentísimo Gobierno Nacional para ofrecerles los instrumentos de labranza que necesitaran, suministrándoles los granos y proporcionándoles los bueyes, asimismo para la fundación de Pueblos donde fuese del mejor agrado de ellos y la erección de un templo colocando en él un sacerdote". AGPSF. Archivo de Gobierno, T. 16 , fs. $1068-1077$. ganado que se expresa como una amenaza para la sociedad criolla. Si realizáramos una lectura lineal, apegados a la propuesta narrativa del registro documental, podríamos aceptar esta forma de clasificar. Pero, ¿es esta realmente representativa de los acontecimientos que se suceden en este contexto fronterizo?, ¿qué pasaría si pusiéramos nuestra mirada en aquellos nombres de caciques, jefes y mediadores?

\section{“Montaraces" y "reducidos", sus prácticas y trayectorias}

A partir de ahora nos concentraremos principalmente en dos actores indígenas que circularon por diversos enclaves fronterizos de Santa Fe, Córdoba y Santiago del Estero. Esperamos que los registros nos proporcionen una visión más completa sobre las prácticas políticas de los actores indígenas, no solo a través de la información que contienen sino también a través de sus omisiones y silencios.

\section{Bonifacio: entre Santa Fe y Santiago del Estero}

Basándonos en un extracto del diario de viaje redactado en marzo de 1857 por Esteban Rams, empresario encargado por el gobierno de la Confederación para estudiar la navegabilidad del río Salado, pudimos identificar ciertos actores indígenas de "tierra adentro". ${ }^{14}$ Dada la baja corriente del río, la embarcación en la que se encontraba Rams, quien se dirigía hacia Santiago del Estero, quedó anclada en Monte Aguará, espacio frecuentemente mencionado como asentamiento indígena (Cervera, 1970 Zampa, 2019). Debido a esto se sucedieron encuentros con varios caciques: Roque, Bonifacio, José, Felipe, Nolasco, entre otros. Además durante el tiempo que permaneció la comitiva del empresario en ese punto se produjeron negociaciones y conversaciones que dieron pié a intercambios, bautismos de los hijos de los jefes indígenas y comunicaciones varias, como así también, específicamente, a promesas de asentamiento hacia ${ }^{15}$ el cacique Bonifacio y su gente. A partir de la redacción de Rams podemos comprender que las relaciones con estos jefes indígenas venían siendo mantenidas por el gobernador de Santa Fe, Juan Pablo López, quien les habría avisado previamente de la presencia del empresario.

Nos interesa describir el itinerario que a partir de este encuentro llevó adelante Bonifacio y algunos de sus seguidores, poniendo a prueba de esta manera la mirada que tienen los registros sobre los propios actores indígenas.

Un año más adelante, en septiembre de 1858, algunos de estos caciques fueron mencionados en el testimonio tomado a un cautivo fugado de las tolderías del cacique José María, el cual había sido capturado siete años antes en el departamento de Tulumba por el cacique Javier. El cautivo aseguró que existía una interacción fuerte entre indígenas reducidos en la provincia de Santa Fe con los montaraces, que se movían por todo el frente fronterizo. El oficial redactó sobre esto lo siguiente:

[...] los indios de las reducciones del Sauce, Calchín y San Pedro se hayan en perfecta inteligencia y continuo comercio perjudicial a los intereses del país, con los indios montaraces, que continuamente los indios de las referidas reducciones se reúnen con los montaraces para invadir las provincias de Santa Fe, Córdoba y Santiago, que luego de regresar a las tolderías, se parten 
el robo hecho y que los indios de las reducciones se retiran a sus respectivas reducciones con la parte que les ha cabido del robo [...]. ${ }^{16}$

Tal es así que el cautivo identificó a varios indígenas que provenían de las reducciones franciscanas, entre ellos Manuqui, Minisito y José María quienes eran del cantón del Sauce. Incluso estableció una relación entre Javier y José María como hijo y padre, respectivamente -a quienes denominaría como "los Bonifacio". Luego en la declaración agregó:

[...] ha oído en las conversaciones que los indios reducidos tienen con los montaraces, que el día que el Gobierno los incomodase por su mala conducta, se alzarían en el momento y se incorporarían a las indiadas alzadas para invadir con más frecuencia $[\ldots]^{17}$

Efectivamente, en noviembre del mismo año Bonifacio y sus seguidores se sublevaron en la reducción de San Francisco Solano, fundada a partir de las conversaciones en el vapor de Esteban Rams un año antes. ${ }^{18}$ Luego de saquear la habitación del misionero a cargo, los sublevados se internaron en el Chaco. Así mientras Bonifacio hostilizaba al flamante gobernador Rosendo María Fraga con esta acción, un año más tarde se mostraba como aliado del gobernador de Santiago del Estero, Manuel Taboada. ${ }^{19}$

Posteriormente volvemos a saber de Bonifacio en abril de 1860, momento del regreso de una partida militar que incursionó en el Chaco desde el cantón 6 de Julio para "escarmentar" a los grupos montaraces que se encontraban asentados más allá del Salado. El cacique evitó la confrontación debido a que fue alertado de la aproximación de los militares. ${ }^{20}$

Finalmente el cacique Javier, mencionado anteriormente como hijo de José María de "los Bonifacios", será encontrado en diciembre de 1862 al regreso de una incursión de robo ${ }^{21}$ por Martiniano Charras, quien encabezaba una expedición al norte del Salado con el objetivo de reprimir y dispersar los asentamientos indígenas. Nuevamente en el parte se señaló que las diversas poblaciones habían sido alertadas del avance de las fuerzas militares. ${ }^{22}$

Este breve recorrido por las trayectorias de algunos jefes indígenas nos permitió resaltar varios aspectos que se ocultan detrás de las categorías y relatos de los registros abordados. En primer lugar, la existencia de relaciones comerciales y de parentesco que articularon "ambos lados" de la frontera, atravesando la línea propuesta por las autoridades estatales. En este aspecto, resaltan las relaciones entre padres momentáneamente reducidos con su hijo asentado dentro del Chaco.

En segundo lugar, los testimonios esbozaron una estrategia indígena que implicó establecer múltiples relaciones políticas con diferentes autoridades provinciales y una visión de la conflictividad que llevó a los actores indígenas a evaluar varios escenarios posibles, dependiendo de las condiciones políticas de cada contexto. Es decir, en el caso de que las relaciones de los indígenas con las autoridades de la provincia de Santa Fe se deterioraran, algo aplicable tanto a los reducidos debido a su actividad de robos como a los montaraces sobre ese segmento de la frontera, se habría incrementado la conflictividad abandonando el espacio de la reducción y aumentando la cantidad de incursiones de robo en respuesta. La estrategia de alternar estados de conflictividad -Santa Fe- en un segmento de la frontera con momentos de paz en otro -Santiago del Esteropermitió a determinados grupos indígenas, como el de Bonifacio, explotar la
16. SHE FC. Caja 1, Doc. no 172 y SHE FC. Caja 1, Doc. n 172, Concepción 19/9/1858 Manuel Martín García a los Ministros Luis Cáceres y Lucrecio Vázquez.

17. SHE-FC. Caja 1, Doc. $n^{\circ}$ 172. Concepción, 19/9/1858. Manuel Martín García a los ministros Luis Cáceres y Lucrecio Vázquez. Es necesario aclarar que en ningún momento es transcripta la voz del cautivo, toda la declaración está redactada por el oficial que lo interroga.

18. AGPSF. Libro copiador de Archivo de Gobierno 1858-1859, f 79. 20/11/1858. Carta al Prefecto de las Misiones en San Carlos, de parte del reverendo padre Juan Cassara. También mencionado en Cervera (1970: 107).

19. Archivo Mitre, Fondo Taboada, Doc. $n^{\circ} 880,14 / 03 / 1859$. Quinta Cruz, de Antonino Taboada a Manuel Taboada, sobre el vapor extraviado de Esteban Rams. Bonifacio participa de la búsqueda del mismo en territorio de Santiago del Estero, es considerado "indio amigo".

20. SHE-FC, Caja 1, Doc. $n^{\circ}$ 217. Cantón 6 de Julio, 30/3/186o. En comunicación oficial del Comandante de la Frontera hacia el Norte y la Derecha, Telmo López al Gobernador de la Provincia de Santa Fe Rosendo María Fraga. En la misma informa sobre el cuerpo de Caballería, Guardias Nacionales y Lanceros del Sauce y San Pedro que se internan en el Chaco. Posteriormente anexado se encuentra el informe sobre las acciones llevadas adelante, fechado el 9/4/186o.

21. SHE-FC. Caja 1, Doc. $n^{\circ}$ 305. San Pedro, 1/12/1862. Da cuenta de una incursión que roba ganado en la frontera, donde muere uno de sus propietarios.

22. SHE-FC. Caja 1, Doc. $n^{\circ} 307$. Arroyo del Curupí, 4/12/1862. El informe además detalla la toma de cautivas indígenas, del ganado encontrado y la distribución de bienes entre la tropa. 
23. SHE-FC. Caja 1, Doc. n ${ }^{307 .}$ Arroyo del Curupí, 4/12/1862.

24. AGPSF. Libro copiador de MGyM 1852-186o, fs. 281, 20/12/1858.

25. SHE-FC. Caja 1, Doc. n 251. Original del 23/12/6o. Expulsión de indios de la antigua reducción y protección de ellos por el Gral. Urquiza. Informe redactado por Fray Aurelio Boidi.

26. La denominación "Colonia indígena" es utilizada tanto en las fuentes como en la bibliografía (Dalla-Corte Caballero, 2012), aun siendo parte de la diócesis de Santa Fe y estando administrada por los franciscanos.

27. AGE. Legajos Personales $n^{\circ} 1764$. Coronel Antonio Ezequiel Berón. Se desempeñaba como lefe Militar del departamento de La Paz, provincia de Entre Ríos. Revistó también en el regimiento de la ciudad de Diamante.

28. SHE-FC. Caja 1, Doc. $\mathrm{n}^{\circ} 248$. Departamento de La Paz, 12/6/1861. Comenta Antonio Berón al Gobernador de Entre Ríos la intención de los indígenas de San Javier de conferenciar y hacer respetar las leyes. Diciendo además que "no reiterarán la conducta que antes observaban". multiplicidad de interlocutores existentes a lo largo del dispositivo fronterizo. Además, se presentan las categorías en cuestión como una característica que puede tomarse estratégicamente y luego dejarse, teniendo en cuenta que mediante nuevas negociaciones pueden volver a adquirirse.

En tercer lugar, es necesario mencionar que las comunicaciones entre indígenas que se encontraban en las reducciones y aquellos que estaban en el "Chaco profundo" eran muy fluidas e incluían también a los cuerpos de lanceros indígenas. Esto nos lleva a plantear la complejidad del ejercicio de la autoridad del comandante de cada compañía de lanceros. Como bien señalan Green (2011) y Ratto (2013), estas fuerzas militares contenían hacia dentro diferentes jerarquías que podían acatar o no -dependiendo de la situación- las directivas de los comandantes criollos.

\section{Manuel Días: indígena reducido y "sublevado"}

Luego de haber recorrido sucintamente el itinerario del cacique Bonifacio, quien era identificado como "principal de estas tribus" 23 montaraces, nos preguntamos: ¿qué conductas subyacían a la existencia de grupos considerados reducidos?

Volviendo a 1857, el Gobernador de Santa Fe, Juan Pablo López, tomó la iniciativa de reconstruir la antigua reducción de San Francisco Javier con el objetivo de integrarla a la línea de frontera, la cual había sido despoblada hacia 1833. Más adelante, con el impulso de los reverendos padres de la Orden Franciscana se pudieron retomar los trabajos de repoblación y hacia 1858 ya se había trasladado un grupo ${ }^{24}$ a asentarse en ella. En el marco de esta reconstrucción, uno de los indígenas reducidos temporalmente en Santa Rosa de Calchines, Manuel Días, se dirigió con una gran cantidad de familias a San Javier -incluso antes de tener la autorización de parte del Gobernador para hacerlo. Luego este indígena fue reconocido por la autoridad militar y por Fray Aurelio Boidi -quien se hizo cargo del establecimiento y de la instrucción religiosa- como representante de la población trasladada a San Javier (Dalla-Corte Caballero, 2012).

Tiempo después, hacia el mes de diciembre de 1860, el gobernador de la provincia de Santa Fe, Rosendo María Fraga, tomó la decisión de despoblar la reducción de San Javier y repartió la población entre las misiones de las que provenían anteriormente, ${ }^{25}$ inspirado tal vez en reconocer a esta Colonia Indígena ${ }^{26}$ como un espacio por el cual circuló mucha de la hacienda robada y los principales ejecutores de los robos.

Pero la intervención del Presidente de la Confederación Argentina, Justo José de Urquiza, restableció a los indígenas en San Javier y dispuso el envío de un comandante militar que tuvo la función de instalarse en la localidad, afianzar las relaciones con los caciques allí asentados y organizar el gobierno en el territorio (Fradkin, 2010). Estas acciones, expresaron las diferencias de intereses en torno al establecimiento de la línea defensiva con el Chaco y se privilegió la relación del Estado nacional a través de la figura de su comandante militar, el Coronel Antonio Berón, ${ }^{27}$ con un indígena en particular, Manuel Días. ${ }^{28}$

Debido a los cambios políticos a nivel nacional esta situación duró poco tiempo. En 1862, con el comienzo del gobierno de Bartolomé Mitre se produjeron cambios en todos los gabinetes, incluyendo la Comandancia de la Frontera 
con el Chaco, dependiente del Ministerio de Guerra y Marina y la Inspección General de Armas. Esto repercutió en San Javier con la expulsión de su jefe militar, Antonio Berón. A partir de este momento, junto con Manuel Días, comenzaron a ser referidos como una amenaza por los comandantes militares de las demás colonias indígenas. ${ }^{29}$ No obstante, Manuel Días continuó siendo nombrado como capitán por Berón, quien lo alertó de un posible ataque en su contra de parte del comandante general de la frontera. ${ }^{30}$ En respuesta a esto, durante el mes de mayo de 1862 el por entonces capitán Días se internó con su gente en el Chaco.

También en agosto de 1862 una carta enviada por Martiniano Charras, el flamante comandante de la frontera sobre el Chaco, confirmó la intención de las autoridades militares de desplazar a Manuel Días de su rol de interlocutor frente a la población indígena de San Javier. La correspondencia informó sobre la remisión de un "indio prisionero" a la localidad de San Pedro, enviado por el corregidor de Cayastá. Este indio era Atanacio Obelar, quien dió un testimonio al comandante de la frontera dando cuenta de la autoridad parcial de Manuel Días en San Javier, calificándolo de "altanero". Luego, el testimonio agregó “[...] será mejor asegurarlo [a Obelar], teniéndolo si no es allí, en esa Capital, poniéndole una barra de grillos siquiera por un mes, trayéndolo a este campo y después destinarlo para infante." También caracterizó al prisionero de la siguiente manera: "Obelar es de mucha vivacidad natural y a más de esto, lee y escribe, y con el no hemos de tener que sufrir detrimento en esta frontera por hombres que no se han dejado desengañar". ${ }^{31}$

Entendemos que este último documento terminó de configurar un escenario desfavorable para Manuel Días y el coronel Antonio Berón. Si bien los registros militares de la época no vuelven a referirse a Atanacio Obelar, sí hacen referencia a Ambrosio Obelar quien revistó como comandante militar y fue registrado de esa forma por el comandante de la frontera en partes posteriores.

Hacia fines de 1862 Manuel Días se internó nuevamente en el Chaco, a raíz de unos incidentes provocados por la presencia del gobernador Patricio Cullen en la localidad de San Javier. ${ }^{32}$ Estos dieron comienzo a un ciclo de acontecimientos conflictivos que se extendieron durante todo 1863, en los cuales Manuel Días avanzó sobre San Javier de forma hostil. Así lo informaron los partes de enero, marzo y mayo, momento en que terminó de operarse la transformación de Ambrosio Obelar, de prisionero a comandante de las fuerzas militares que repelieron los "ataques" y que "mantienen el orden" en San Javier. En este marco, Manuel Días será referido junto a Antonio Berón y sus seguidores como "sublevados". Nos detendremos en este punto.

Observamos que durante todo el ciclo de conflictos desde el regreso a San Javier, Manuel Días en ningún momento fue identificado con la categoría de montaraz. Entendemos que esto se debe a que desde la perspectiva de los funcionarios militares se lo considera reducido y debido a esto las estrategias que desplegó el Estado divergen de aquellas que podían ser aplicadas a una población montaraz. En este caso, tanto el comandante de la Frontera, Martiniano Charras, como el propio presidente de la República, Bartolomé Mitre, intentarán intervenir en la "sublevación" a través de una acción sumaria: enviando una comisión para investigar los acontecimientos. Días no será atacado dentro del Chaco, simplemente sus avances serán rechazados sucesivamente. $^{33}$
29. AGPSF. Archivo de Gobierno, T. 22, f. 1661. San José, 12/1/1862. Se refuerzan los cantones frente a la presencia de Antonio Berón, quien conferencia con Días; Archivo de Gobierno, T. 22 f. 1692. San José, 10/5/1862. Avelino Álvarez a Joaquín Granel, ministro de gobierno del gobernador Antonio Crespo.

30. AGPSF. Archivo de Gobierno, T, 22, f. 1661, San José, 12/1/1862; Archivo de Gobierno, T. 22, f. 1692. San José, 10/5/1862.

31. SHE-FC. Caja 1, Doc. $n^{\circ}$ 278. San Pedro, 5/8/1862. Martiniano Charras al secretario general de gobierno de Santa Fe.

32. Según la transcripción de un informe de Fray Boidi sobre la historia de San Javier, hecha por Dalla-Corte Caballero (2012: 63), sabemos que a raíz de la muerte de prisioneros que el Gobernador había tomado en el pueblo Manuel Días se subleva atacando a los misioneros.

33. SHE-FC. Caja 2, Doc. $n^{\circ} 32$. $12 / 3 / 63$. Regresa Manuel Días a San lavier, los pobladores y el encargado de la reducción huyen a Esquina Grande; SHE-FC. Caja 2, Doc. n 49. San Pedro, $1 / 5 / 63$. Se restablece el orden en San Javier, el comandante indígena Obelar se hace cargo de la vigilancia de la misma. 
34. Según Cervera (1970: 104-105) los antiguos pobladores de la misión de Jesús Nazareno de Inspín, fundada en 1795 y despoblada en la segunda década del siglo XIX, serían llamados "inspineros" O "espineros". Estos habrían "quedado en el monte y errantes", junto a pobladores de otras reducciones desaparecidas. La presencia de esta denominación específica nos propone nuevos interrogantes acerca de las poblaciones indígenas en torno al río Salado durante la primera mitad del siglo XIX.

35. SHE-FC. Caja 2, Doc. ${ }^{\circ}$ 15. Cantón San Pedro, 13/1/63. Sublevación de Manuel Días, luego se interna en el chaco con su gente; SHE-FC. Caja 2, Doc. $n^{\circ}$ 6o. Julio de 1863 , nuevo acercamiento de Días, esta vez queriendo parlamentar. Días y sus aliados son presentados como "demonios".

36. SHE-FC. Caja 2, Doc. $n^{\circ} 6$ o. Julio de 1863.

37. SHE-FC. Caja 2, Doc. $n^{\circ}$ 135. San Javier, 16/2/1864. Informe de Obelar sobre los indígenas que retornan a San Javier.
Finalmente en julio de 1863 Manuel Días avanzó por última vez sobre San Javier junto a "espineros", ${ }^{34}$ montaraces y tobas. ${ }^{35}$ Se mencionó que al ser sentidos los atacantes durante su llegada a San Javier, estos cambiaron de intenciones y expresaron que acudieron a la misma a "reducirse con su familia y hacer las pases con el gobierno". ${ }^{36}$ Por varias razones desconfiamos del carácter de hostilidad que manifestaron los registros, principalmente por la existencia previa de una intención expresa de llegar a una negociación con las autoridades a cargo de la colonia que, contrastándola con el caso anteriormente tratado, podría ser parte de una estrategia que combinara el planteo de una situación de hostilidad con el objetivo de obtener condiciones de negociación más favorables.

El fracaso en la negociación llevó a Manuel Días de regreso hacia el Chaco, luego de ser perseguido por diferentes fuerzas militares. La última referencia a Manuel Días surgió de un parte escrito por Ambrosio Obelar en marzo de 1864, donde expresó que aquel y otros caciques que anteriormente habían hostilizado la colonia San Javier obtuvieron un indulto del gobernador de la provincia, habiendo logrado asentarse junto a sus familias en ella. ${ }^{37}$

La intervención del gobierno nacional, provincial y del comandante de la frontera sobre el Chaco en la construcción de la autoridad del líder indígena forma parte de una estrategia que, como señalaron Green (2011), Ratto (2013) y Molina y Green (2015), buscó la posibilidad de movilizar a la población indígena como fuerza militar auxiliar. Si esto no era posible, la reducción o bien la represión violenta solían ser las posibilidades habituales para la resolución de conflictos. En el caso particular de Manuel Días pudimos observar que su accionar independiente, al no respetar las órdenes de las autoridades provinciales -primero de Juan Pablo López, luego de Patricio Cullen- muy probablemente lo haya colocado en una posición frágil a la hora de mantenerse como mediador o representante de su grupo frente a aquellas. Esta actitud oscilante entre el acatamiento y la desobediencia en actores indígenas en este contexto ha sido retratada por Green (2011). Los resultados de esta estrategia fueron finalmente satisfactorios, ya que tanto Manuel Días como algunos de sus aliados lograron volver a asentarse dentro de San Javier.

El cambio de orientación política, primero del gobierno provincial despoblando San Javier, y luego del gobierno nacional, cambiando los actores militares de la frontera, enfrentaron a Manuel Días y Antonio Berón con las autoridades militares, quienes los presentaron como "sublevados" más no como "montaraces". Arriesgaremos aquí una interpretación: parecería ser que las categorías construidas desde los actores militares sobre los indígenas fueron verdaderamente operativas y se correspondieron con estrategias de contacto diferentes en cada caso. Aún más, desde la perspectiva militar no parece posible trasladarse de una categoría a la otra muy fácilmente.

Esto nos llevó a replantear la manera en que las fuentes militares presentaron a los actores indígenas en la frontera, poniendo el foco en el tipo de acontecimientos en que se los circunscribió y bajo qué rótulos. Este discurso de los actores que relataron los acontecimientos se caracterizó, como vimos, por ocultar los aspectos políticos que fundamentaron las acciones que protagonizaron Bonifacio, Manuel Días, Antonio Berón y otros.

En cuanto a los rótulos de montaraz y reducido hay que mencionar que solo pudieron ser relativizados por el análisis de las trayectorias de los actores indígenas que hemos intentado reconstruir. Aunque estas categorías parecen corresponderse con un grupo específico de indígenas desde la mirada de los 
militares, las estrategias desplegadas por los indígenas parecen rebasarlas. Por un lado, tanto Bonifacio como Manuel Días y sus aliados formaron parte de poblaciones reducidas y mantuvieron su movilidad también "tierra adentro" del Chaco, participaron de robos de ganado, toma de cautivos y acciones de insurrección a lo largo de toda la frontera. Por el otro, articularon hábilmente múltiples alianzas con actores estatales diversos, explotando muchas veces las competencias y jurisdicciones diferentes que existían entre los mismos. Es así que los rótulos propuestos por las fuentes devinieron en denominaciones que englobaron una multitud de grupos indígenas bajo una taxonomía binaria que dependió de su ubicación en el territorio y de sus relaciones con el Estado.

\section{Palabras finales}

A través de la reconstrucción de las trayectorias de algunos caciques y líderes indígenas que se hallaban en interacción con las autoridades militares de la frontera norte de la provincia de Santa Fe pudimos caracterizar las múltiples facetas que implicó el desarrollo de una estrategia política del Estado en las décadas de 1850-1860, con el fin de lograr la paulatina anexión de nuevos territorios y poblaciones.

En un primer plano este análisis nos llevó a identificar las categorías utilizadas principalmente por actores militares para definir y clasificar a la población indígena, como montaraz o reducido. Pudimos observar cómo a estas les eran atribuidos patrones de acción entendidos como "robos", "ataques" e "invasiones" presentándolos como su principal forma de intervención. De esta manera, y siguiendo a Boccara (2003), observamos que el despliegue de una estrategia militar de defensa de la frontera implicó la construcción de un dispositivo clasificatorio del "otro indígena", creando una visión de éste ajustada a las prácticas y necesidades del avance territorial.

En un segundo plano, a través de estos mismos registros documentales y siguiendo las trayectorias de algunos actores indígenas, pudimos identificar una serie de prácticas políticas comunes que condicionaron efectivamente a los gobiernos nacionales y provinciales, articulando en sus dinámicas de movilidad a los enclaves reduccionales y militares con los espacios "tierra adentro". Se utilizaron las estrategias desplegadas por el Estado para incorporar al "otro" en una construcción dinámica del sí-mismo (Boccara, 2003). La definición de liderazgo reconocida por el Estado, la participación en los cuerpos de lanceros auxiliares y el asentamiento en las reducciones se combinaron, al mismo tiempo, con el asalto a provincias limítrofes para la obtención de cautivos que potenciaran sus estrategias de intercambio fronterizo.

Este escenario también se caracterizó por las alianzas tendidas entre múltiples parcialidades indígenas y por la inestabilidad de sus articulaciones políticas con las autoridades del Estado, generando un complejo y cambiante contexto político -acentuado por la sucesión de gobernadores y autoridades nacionales que repercuten en los actores situados en la frontera.

Por último debemos mencionar que habiendo sido la dicotomía entre montaraz y reducido parte integral del despliegue político del Estado sobre el Chaco, habilitó prácticas dirigidas al ordenamiento de la conducta indígena y a la represión de aquellos sectores que no se sometieran a los planes estatales. Pero observar los acontecimientos a través de esta lente nos llevaría a una visión estéril, inmóvil y esencializada de las poblaciones indígenas. Esta dimensión 
de las fuentes, que tiende a obliterar y reducir el accionar del "otro indígena", nos señala -probablemente sin quererlo- el carácter interdigitado y permanentemente negociado de la identidad de los mismos en este periodo particular del siglo XIX.

\section{Agradecimientos}

A los atentos consejos, oportunas correcciones y dedicados esfuerzos de la Dra. Ingrid de Jong, la Srta. Lourdes Rolando y el Lic. Julián Trovero para mejorar este escrito. 


\section{Archivos y fuentes documentales citadas}

»Archivo General del Ejército (AGE) Buenos Aires, Argentina.

Legajos personales $n^{\circ} 1764$.

»Archivo General de la Provincia de Santa Fe (AGPSF).

Archivo de Gobierno T. 16, fs. 1068-1077; T. 20, fs. 1132-1133; T. 22, f. 1661; T. 22, f. 1692.

Libro copiador de Archivo de Gobierno 1858-1859, f. 79.

Libro copiador del Ministerio de Guerra y Marina (MGyM) 1852-186o, f. 281.

» Archivo Mitre Fondo Familia Taboada, Doc. № 880.

»Servicio Histórico del Ejército (SHE). Fondo Frontera con el Indio, Frontera Chaco (FC).

Caja 1. Docs. $n^{\circ} 128,172-175,187-189,207-209,217,248,251,278,305,307$.

Caja 2. Docs. $n^{\circ} 15,32,49,60,135$.

Listas de Revista - Libro 231. 


\section{Q Bibliografía}

"Alemán, B. (1970). “El problema del indio en la historia de Santa Fe: desde la Revolución hasta la organización nacional” en Historias de las instituciones de la provincia de Santa Fe. Tomo III (Oficial): 39-85. Santa Fe, Comisión redactora de las instituciones de la provincia.

" Boccara, G. (2003). "Fronteras, mestizaje y etnogénesis en las americas" en Mandrini, R. y C. Paz (eds.), Las fronteras hispanocriollas del mundo indígena latinoamericano en los siglos XVIII y XIX: 63-108. Tandil, IEHS, CEHIR, UNS.

"Caloni, V. (1897). Bosquejo histórico de las Misiones Franciscanas al norte de la provincia de Santa Fe. Santa Fe, Establecimiento Tipo-Litográfico J. Benaprés.

"Cervera, F. (1970). "Las reducciones indígenas en el periodo independiente", en Historias de las instituciones de la provincia de Santa Fe. Tomo III (Oficial): 89- 110. Santa Fe, Comisión redactora de las instituciones de la provincia.

"Citro, S. (2006). Tácticas de invisibilización y estrategias de resistencia de los mocoví santafesinos en el contexto postcolonial. Revista Indiana Instituto Iberoamericano 23:139170.

»Citro, S. (2007). "Las estéticas del poder: liderazgos y performances rituales entre los mocoví santafesinos", en Braunstein, J. y N. Meichtry (eds.), Liderazgos en el Gran Chaco: s/pp. Resistencia, Universidad Nacional del Nordeste.

»Dalla-Corte Caballero, G. (2012). Mocovíes, franciscanos y colonos de la zona chaqueña de Santa Fe [1850-2011]: El liderazgo de la mocoví Dora Salteño. Rosario, Prohistoria.

»Dalla-Corte Caballero, G. y F. Vázquez Recalde (2010). La conquista y ocupación de la frontera del Chaco entre Paraguay y Argentina: los indígenas tobas y pilagás y el mundo religioso en la Misión Tacaaglé del Río Pilcomayo. Barcelona, TEIAA.

»Dobrizhoffer, M. ([1783] 1967). Historia de los abipones. Resistencia, UNNE.

" Dosztal, I. (2013). El norte santafesino, una frontera de colonización entre la barbarie y la civilización, 1860-1880. Cuadernos de Antropología 9: 227-250.

"Farberman, J. (2006). Recolección, economía campesina y representaciones de los montaraces en Santiago del Estero, siglos XVI a XIX. Prohistoria 10 (10): 11-26.

» Fradkin, R. (2010). “Notas para una historia larga: comandantes militares y gobierno local en tiempos de guerra" en Bragoni, B. y M. Miguez (comps.), Un nuevo orden político: provincias y el estado nacional, 1852-1880: 293-306. Buenos Aires, Biblos.

"Green, A. (2005)."El escuadrón de lanceros del Sauce. Una aproximación a las transformaciones operadas en una sociedad india durante la $19^{\circ}$ centuria" ponencia presentada en el Congreso Argentino de Inmigración. Secretaría de Cultura de la provincia de santa Fe, Municipalidad de la ciudad de Esperanza, Archivo General de la provincia de Santa Fe, Centro de Estudios e Investigaciones Históricas del Departamento Las Colonial y Junta Provincial de Estudios Históricos. Esperanza, Santa Fe, 10 al 12 de noviembre.

» Green, A. (2007). “El alzamiento de los indios del Sauce (1836-1837): una aproximación a la sociedad abipona de la época y el último acto de su resistencia activa a la dominación del hombre blanco" ponencia presentada en el II Congreso Regional de Historia e Historiografía. Facultad de Humanidades y Ciencias (FHUC), Universidad Nacional del Litoral (UNL). Santa Fe, 3 y 4 de mayo. 
» Green, A. (2011). “Entre la Tribu y el Estado. Estrategias de supervivencia y opciones políticas de los 'oficiales' mocovíes de la frontera norte santafecina a mediados del siglo XIX” ponencia presentada en el IV Congreso Regional de Historia e Historiografía. Facultad de Humanidades y Ciencias (FHUC), Universidad Nacional del Litoral (UNL). Santa Fe, 12 y 13 de mayo

»Lázaro Ávila, C. (1999). Conquista, control y convicción: el papel de los parlamentos indígenas en México, el Chaco y Norteamérica. Revista de Indias, 59 (217): 645-673.

» Levaggi, A. (200o). Paz en la Frontera: Historia de las relaciones diplomáticas con las comunidades indígenas en la Argentina (Siglos XVI-XX). Buenos Aires, Universidad del Museo Social Argentino.

»Lucaioli, C. (2009). Alianzas y estrategias de los líderes indígenas abipones en un espacio fronterizo colonial (Chaco, siglo XVIII). Revista Española de Antropología Americana 39 (1): 77-96.

» Lucaioli, C. (2011). Abipones en las fronteras del Chaco. Buenos Aires, Sociedad Argentina de Antropología (SAA).

» Lucaioli, C. y L. Nacuzzi (2010). Fronteras: Espacios de interacción en las tierras bajas del sur de América. Buenos Aires, SAA.

» Maffucci Moore, J. L. (2007). Indios, Inmigrantes y Criollos en el Nordeste Santafesino (1860-189o): Un caso de violencia en una sociedad de frontera. Andes (18): 275-302.

» Molina, G y A. Green (2015). “La incorporación de contingentes indígenas en las fuerzas militares de la sociedad criolla, en la frontera norte santafesina durante el s. XIX" ponencia presentada en el VI Congreso Regional de Historia e Historiografía. Facultad de Humanidades y Ciencias (FHUC), Universidad Nacional del Litoral (UNL).

»Santa Fe, 28 y 29 de mayo.

»Nacuzzi, L. (2018). Entre los datos y los formatos: indicios para la historia indígena de las fronteras en los archivos coloniales. Buenos Aires, IDES-CONICET.

» Nacuzzi, L. y C. Lucaioli (2017). Una reflexión sobre los rótulos históricos y la dificultad de nombrar a los grupos étnicos de Pampa-Patagonia y el Chaco. Nuevos Mundos Mundos Nuevos. Debates: 1-22.

》 Nesis, F. S. (2005). Los grupos Mocoví en el Siglo XVIII. Buenos Aires, SAA.

» Paucke, F. ([1942] 2010). Hacia allá y para acá : memorias. Santa Fe, Ministerio de Innovación y Cultura de la Provincia de Santa Fe.

» Paz, C. D. (2007). Conflictos y redes sociales en el proceso de legitimación del poder indígena. Andes (18): 251-274.

» Ratto, S. (2013). “Resistencia y movilización entre los indios fronterizos del Chaco”, en Fradkin, R. y G. Di Meglio (eds.) Hacer Política: la participación popular en el siglo XIX rioplatense. Buenos Aires, Prometeo Editores.

» Ratto, S. y R. Fradkin (2011). Reducciones, blandengues y el enjambre de indios del chaco: entre las guerras coloniales de frontera y las guerras de revolución en el norte santafesino. Folia Historica del Nordeste 20: 23-48.

» Tola, F., Medrano, C. y L. Cardin (eds.) (2013). Gran Chaco : Ontologías, poder, afectividad. Buenos Aires, Asociación Civil Rumbo Sur.

»Zampa, R. (2019). Entre la autonomía provincial y el proyecto nacional : la frontera norte santafesina en tiempos de la Confederación Argentina, 1852-1861. Quinto Sol 23 (2): 1-19. 